\title{
Verzeichnis der wichtigsten Abkürzungen für Literaturangaben.
}

ALL: Archiv für lateinische Lexikographie und Grammatik, hrg, von W. Wölfflin.

Atl. ling.: J. Gilliéron, Atlas linguistique de la France.

Bauer: A. Bauer, Der Fall der Pänultima und seine Beziehungen zur Erweichung der intervokalen Tenuis zur Media und zur Vokalveränderung in betonter freier Silbe. Diss. Würzburg 1903.

Berger: H. Berger, Die Lehnwörter in der französischen Sprache ältester Zeit. Leipzig I899.

Clédat: Léon Clédat, Sur le traitement de $\mathbf{C}$ après la Protonique et la Pénultrème atones; Consonnes intervocales après la protonique et la pénultième atones. Revue de philologie française et de littérature XVII (1903) 122-138, 209-228.

Dict. gén.: Hatzfeld et Darmesteter, Dictionnaire général de la langue française. Paris (I88 ff.).

Diez: Diez, Etymologisches Wörterbuch der romanischen Sprachen. 5. Ausgabe (1887).

Elirath: H. Elfrath, Die Entwicklung lateinischer und romanischer Dreikonsonanz im Altfranzösischen. Rom. Forsch. X (1899).

God.: F. Godefroy, Dictionnaire de l'ancienne langue française et de tous ses dialectes du IXe au XVe sizcle, Bd. I-IO, Paris I880-I90I.

Gr.: Grundrifs der romanischen Philologie, hrg. von G. Gröber. Band I, 2. Aufl. (1904-06).

Gutheim: F. Gutheim, Über Konsonanten-Assimilation im Französischen. Diss. Bern I89I.

Herford: H. Herford, Die lateinischen Proparoxytona im Altprovenzalischen. Diss. Königsberg 1907 .

Herzog: E. Herzog, Streitfragen der romanischen Pbilologie I. Halle 1904.

Hetzer: K. Hetzer, Die Reichenauer Glossen. Halle I906.

Horning, Prop.: A. Horning, Die Behandlung der lateinischen Proparoxytona in den Mundarten der Vogesen und im Wallonischen. Programm Strafsburg 1902.

Karsten: P. Karsten, Zur Geschichte der afr. Konsonanten-Verbindungen. Diss. Freiburg 1884.

Klausing: P. Klausing, Die Schicksale der lateinischen Proparoxytona im Französischen. Diss. Kiel I900. 
Körting: G. Körting, Lateinisch-romanisches Wörterbuch. I.-3. Auf 1.

Lindström: Anmärkningar till de obetonade vokalernas bortfall i några nordfranskar ortnamn. Diss. Upsala 1892.

Marchot: P. Marchot, Petite phonétique du français prélittéraire (VIe-Xe siècles). Freiburg Igor f.

M.-L.: W. Meyer-Lübke.

- Bet. im Gall.: Die Betonung im Gallischen. Sitz.-Ber. der kais. Akad. d. Wiss. in Wien, phil.-hist. Klasse CXIIII (I90I).

- Einf.: Einführung in das Studium der romanischen Sprachwissenschaft. Heidelberg Igor.

- Frz. Gr.: Historische Grammatik der französischen Sprache. Heidelberg 1908.

- Rom. Gr.: Grammatik der romanischen Sprachen. Leipzig I890-I90I.

Nyrop: Kr. Nyrop, Grammaire historique de la langue française. I. Bd. 2. Auf. 1904, 2. Bd. 1903, Kopenhagen.

Rom.: Romania.

Schw.-B.: Schwan-Behrens, Grammatik des Altfranzösischen. 7. Aufl. Leipzig 1907.

Schuchardt R. E.: H. Schuchardt, Romanische Etymologien. Sitz.-Ber. der kais. Akad. d. Wiss. in Wien, phil.-hist. KI. Bd. 139 und $14 \mathrm{I}$ (1898, 99).

Shepard: W. P. Shepard, A Contribution to the History of the Unaccented Vowels in Old French. Diss. Heidelberg 1897 .

Walde: A. Walde, Lateinisches etymologisches Wörterbuch, Heidelberg 1906.

Zeitschr.: Zeitschrift für romanische Philologie. 